\title{
Kinetic parameters of red pepper waste as biomass to solid biofuel
}

\author{
Amanda Alves Domingos Maia, Leandro Cardoso de Morais*

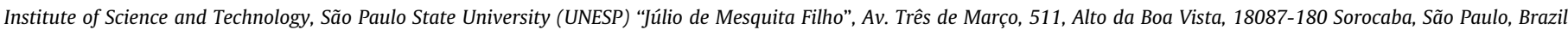

\section{H I G H L I G H T S}

- Thermochemical conversion of biomass residues.

- Bioenergy.

- Kinetic study of biomass.

- Solid biofuel.

\section{A R T I C L E I N F O}

\section{Article history:}

Received 19 November 2015

Received in revised form 17 December 2015

Accepted 19 December 2015

Available online 31 December 2015

\section{Keywords:}

Bioenergy

Biomass

Calorific value

Kinetics parameters

Thermal analysis

\begin{abstract}
A B S T R A C T
This work aimed to study the kinetic of thermal degradation of red pepper waste as solid biofuel to bioenergy production. The thermal degradation experiments were conducted at three heating rates, $5^{\circ} \mathrm{C} / \mathrm{min}$, $7.5^{\circ} \mathrm{C} / \mathrm{min}$ and $10^{\circ} \mathrm{C} / \mathrm{min}$ in a thermogravimetric analyzer and oxidative atmosphere. The kinetic analysis was carried out applying the isoconversional model of Ozawa-Flynn-Wall. The activation energy was considerate low and varied $29.49-147.25 \mathrm{~kJ} / \mathrm{mol}$. The enthalpies revealed the energy difference between the reagent and the activated complex agreed with activation energies, the values of the pre-exponential factor indicated empirical first order reactions, Gibbs free energy varied from $71.77 \mathrm{~kJ} / \mathrm{mol}$ to $207.03 \mathrm{~kJ} / \mathrm{mol}$ and the changes of entropies had negative values, indicating that the degree of disorder of products formed through bond dissociations was lower than initial reactants. The calorific value was $19.5 \mathrm{MJ} / \mathrm{kg}$, considered a relevant result for bioenergy production.
\end{abstract}

(c) 2015 Elsevier Ltd. All rights reserved.

\section{Introduction}

The agro-industry generates a large quantity the residues, also called biomass, which may be employed in the bioenergy generation. Several wastes are being used as biomass, including seeds, sewage sludge, leaves and algae (Santos et al., 2015b).

Worldwide data shows 1.3 billion of tons of food are wasted yearly which is equivalent to 750 billion dollars a year of damage (Food and Agriculture Organization, 2015).

Health-promoting, nutritional and sensory attributes make pepper as one of the most worldwide consumed vegetable (García, 2011) and Capsicum sp. powder is one of the most important spices. However, studies of the reuse and thermochemical properties of these residues have not been investigated (Santos et al., 2015b).

The red peppers cultivation has a greater importance and is considered the second most exported vegetable, encompassing

\footnotetext{
* Corresponding author. Tel.: +55 (15) 3238 3400x3429; fax: +55 (15) 32282842 E-mail address: leandro@sorocaba.unesp.br (L.C. de Morais).
}

an annual worldwide production of 30 million tons in an acreage of 4 million ha (Freibauer et al., 2011).

The production of this fruit is considered one of the most important, representing the third in production and vegetable consumption, second only to garlic and onion (Milagres, 2014).

The quality and quantity of the obtained bioenergy depend not only on the chemical composition of original biomass but also on the reaction conditions. Thus, it is important to understand the chemistry of this alternative biomass in order to know the thermochemically conversion process into biomass-derived fuels (Lee et al., 2014).

This paper examines thermochemical red pepper waste conversion including thermodynamic parameters for non-isothermal analyses using Ozawa-Flynn-Wall (OFW) kinetic isoconversional model. Then the values of apparent activation energy $\left(E_{\alpha}\right)$, preexponential factor $(A)$ in Arrhenius equation, as well as the changes of entropy $(\Delta S)$, enthalpy $(\Delta H)$ and free Gibbs energy $(\Delta G)$ were calculated. The calorific value was determined by calorimetric bomb. 


\section{Methods}

\subsection{Sample preparation}

The biomass of this study was the red pepper, Capsicum baccatum var. pendulum, waste. At the laboratory, the biomass was washed in tap water and dried naturally at room temperature for $24 \mathrm{~h}$, followed by oven drying Solab model SL-100/42 at $105^{\circ} \mathrm{C}$ to constant weight. The whole process lasted about seven days. After drying, the samples were ground in a Wiley mill, MA048 - Marconi, followed by sieving, Solotest sieve, NBR \#200 (0.074 mm).

\subsection{Thermal analysis}

Thermogravimetric analysis were carried out at three different heating rates, $5^{\circ}, 7.5^{\circ}$ and $10^{\circ} \mathrm{Cmin}^{-1}$, using a simultaneous DSC-TGA equipment, TA Instruments, model SDT Q600, from $25^{\circ} \mathrm{C}$ to $1000{ }^{\circ} \mathrm{C}$. Air was used as purge gas at a $120 \mathrm{ml} \mathrm{min}^{-1}$ flow rate. About (1.5 mg) of the biomass were used in alumina pans in each analysis. The TA Instruments software provides the thermogravimetry (TG) and derivative thermogravimetry (DTG) curves.

\subsubsection{Calorific value}

It was used a Calorimetric Bomb IKA C-200 and about $0.5 \mathrm{~g}$ was used for $10 \mathrm{~min}$ with $99.5 \%$ pure oxygen.

\subsection{Kinetic study}

As a matter of fact, the isoconversional analysis provides a fortunate compromise between the oversimplified but widely used single-step Arrhenius kinetic treatments and the prevalent occurrence of processes whose kinetics are multi-step (Vyazovkin and Sbirrazzuoli, 2006).

The one-step global model assumes that the degradation processes results in a single reaction, below.

\section{Biomass $\stackrel{k}{\rightarrow}$ Volatiles + Biochar}

$k$ is defined as the rate constant of reaction whose temperature dependence is expressed by the Arrhenius equation

$k=\mathrm{Ae}^{\left(-E_{a} / R T\right)}$

where:

$E_{\mathrm{a}}$ apparent activation energy $(\mathrm{kJ} / \mathrm{mol})$;

$T$ is the absolute temperature (K);

$R$ universal gas constant $8.31 \mathrm{~J} / \mathrm{K} \mathrm{mol}^{-1}$;

$A$ is the pre- exponential factor $\left(\mathrm{s}^{-1}\right)$.

The rate of transformation from solid-state to volatile product is described by the following expression:

$\frac{d_{\alpha}}{d_{t}}=k(T) f(\alpha)$

where:

$A$ is conversion degree of the process;

$k(T)$ is the time of process;

$f(\alpha)$ is the rate constant and the reaction model.

Conversion, $\alpha$, represent the normalized form of weight loss data of decomposed sample and is defined as below:

$\alpha=\frac{m_{i}-m_{\alpha}}{m_{i}-m_{f}}$

where:

$m_{\mathrm{i}}$ is the initial mass of the sample;

$m_{\alpha}$ is the actual mass;

$m_{\mathrm{f}}$ is the mass after combustion.
Combining Eqs. (1) and (2) gives the fundamental expression (4) of analytical methods to calculate kinetic parameters, on the basis of TG results.

$\frac{d_{\alpha}}{d_{t}}=A * f(\alpha) * e^{-E_{a} / R T}$

The expression of the function $f(\alpha)$ and its derivative $f(a)$ are used for describing solid-state first order reaction:

$f(\alpha)=(1-\alpha)^{n}$

where:

$n$ is the order reaction.

Substituting expression (5) into Eq. (4) gives the expression of reaction rate in the form:

$\frac{d_{\alpha}}{d_{t}}=A *(1-\alpha)^{n} * e^{E_{a} / R T}$

For non-isothermal TG/DTG experiments at linear heating rate $\beta=d \mathrm{~T} / d \mathrm{t}$, Eq. (6) can be written as:

$\frac{d_{\alpha}}{d_{t}}=\frac{A}{\beta} *(1-\alpha)^{n} * e^{-E_{a} / R T}$

This equation expresses the fraction of material consumed in the time. In this work the activation energy was obtained from non-isothermal TG/DTG. The methods used to calculate kinetic parameters were non-isothermal and isoconversional OzawaFlynn-Wall methods and required tests at different heating rates.

\subsubsection{Ozawa-Flynn-Wall methods}

Kinetic analysis is essential to design and establish efficient, safe and reasonable processes. Determination of thermo-kinetic behavior of biomass allows control of decomposition mechanism of biomass. Kinetic parameters of reaction are necessary for accurately prediction of reactions behavior and optimization of the process towards products during thermal degradation (Ceylan and Topçu, 2014). Non-isothermal thermogravimetric analysis is the most popular and simplest method to study the kinetics and thermodynamics properties of biomass. An isoconversional integral method seems to be a safer alternative for the calculation of meaningful activation energy values for certain prerequisites, without knowing the kinetic model of the reaction mechanism.

The Ozawa-Flynn-Wall kinetics isoconversional method Eq. (8) was applied (Kim et al., 2010).

$\ln (\beta)=C_{\alpha}-\frac{E_{\alpha}}{R \cdot T}$

where:

$\beta$ heating rate;

$E_{\alpha}$ apparent activation energy;

$C_{\alpha}$ function of the conversion degree $\alpha$;

$R$ universal gas constant $8.31 \mathrm{~J} / \mathrm{K} \mathrm{mol}^{-1}$;

$T$ the absolute temperature (K).

It was applied at least three values of heating rate $(\beta)$ for different and same values of $\alpha$ in different absolute temperatures $(T)$ in Kelvin (K) obtained at thermogravimetric curves. Allows to investigate whether the mechanism of the conversion is changing with the conversion degree, estimating the respective activation energy $E_{\alpha}$ at a conversion degree $\alpha$. To calculate the kinetic parameters this work used an intermediate value of $\beta\left(7.5^{\circ} \mathrm{C} / \mathrm{min}\right)$.

The thermodynamic parameters using OFW isoconversional method for analysis of kinetic studies and thermodynamic parameters including pre-exponential factor $(A)$ in Arrhenius equation, as well as enthalpy $(\Delta H)$, free Gibbs energy $(\Delta G)$ and the changes of 
entropy $(\Delta S)$ can be expressed by Eqs. (9)-(12) (Kim et al., 2010; $\mathrm{Xu}$ and Chen, 2013).

$A=\beta \cdot E_{\alpha} \exp \left(\frac{E_{\alpha}}{R \cdot T m}\right) / R \cdot \operatorname{Tm}^{2}$

$\Delta H=E_{\alpha}-R T$

$\Delta G=E_{\alpha}+R \cdot T m \cdot \ln \left(\frac{K_{\mathrm{B}} \cdot T m}{\mathrm{~h} \cdot A}\right)$

$\Delta S=\frac{\Delta H-\Delta G}{T m}$

where:

$K_{\mathrm{B}}$ Boltzmann constant $\left(1.381 \cdot 10^{-23} \mathrm{~J} / \mathrm{K}\right)$; h Plank constant $\left(6.626 \cdot 10^{-34} \mathrm{~J} \mathrm{~s}\right)$;

Tm DTG peak temperature.

\section{Results and discussion}

\subsection{Thermogravimetric analysis}

Previous studies showed that biomass degradation can be divided into individual steps: water devolatilisation, hemicellulose, cellulose and lignin decomposition (Font et al., 2005). The decomposition of any biomass can be considered as the superposition of this main components (Manyà and Arauzo, 2008). This process is characterized by combustion of the residue formed, pyrolysis and oxidative pyrolysis (Conesa et al., 2014).

Thermal decomposition of lignin can occurs in a temperature range from $180^{\circ} \mathrm{C}$ to $900{ }^{\circ} \mathrm{C}$, and mass loss rate is not as clear as in the case of hemicellulose and cellulose that decomposition has been estimated to be about $220-315^{\circ} \mathrm{C}$ and $315-400{ }^{\circ} \mathrm{C}$, with a maximum mass loss rate of about $268^{\circ} \mathrm{C}$ and $355^{\circ} \mathrm{C}$ (Gašparoviè, 2012).

The trends in weight loss curves obtained during the TG/DTG shows the physical and chemical structural changes occurring during the thermal conversion. Differential thermogravimetry (DTG) curve indicates main devolatilisation stages more clearly (Ceylan and Kazan, 2015). The curves have the typical appearance of degradation of lignocellulosic biomass just like the DTG curves obtained for the pyrolysis of cardoon leaves and stems at a heating rate of $10^{\circ} \mathrm{C} / \mathrm{min}$ (Xu and Chen, 2013) and the weight loss profile provided the instantaneous biomass weight at specific temperatures as biomass temperature was increased.

During the thermal degradation process up to $1000^{\circ} \mathrm{C}$ with the heating rate of $5{ }^{\circ} \mathrm{C} / \mathrm{min}, 7.5^{\circ} \mathrm{C} / \mathrm{min}$ and $10^{\circ} \mathrm{C} / \mathrm{min}$, around 96.83 wt.\%, 97.12 wt.\% and 93.90 wt.\% of the biomass can be volatilized, with a $3.17 \%, 2.87 \%$ and $6.09 \%$ of residual materials, respectively. The biochar formation was in a range of $200-440{ }^{\circ} \mathrm{C}$ and the ash contents displayed a positive correlation with degradation temperature (Xu and Chen, 2013). The presence of oxygen produces partial oxygenation of solid material, causing the apparent delay in the decomposition of the biomass.

This biomass allows producing biochar at lower temperature and biochar derived from herbaceous residues probably has distinct properties than that based on other plants (Lian et al., 2014).

Thermal analyses in the presence of oxygen, given the high exothermicity of the combustion reactions, a thermal decomposition may occur with the temperature inside the sample becoming considerably higher than that usual and the sample being oxidized at high reaction rate (di Blasi, 2009).

Fig. 1 demonstrates an example of a set of TG (A) and DTG (B) curves of DRP, obtained at $5^{\circ} \mathrm{C} / \mathrm{min}, 7.5^{\circ} \mathrm{C} / \mathrm{min}$ and $10^{\circ} \mathrm{C} / \mathrm{min}$ heating rates in air atmosphere. The thermal analysis data show that the system is complex by the presence of overlapping reaction sequences and because of the complexity of the biomass samples of agricultural origin (CONESA; URUEÑA; DÍEZ, 2014).

Therefore, the thermal decomposition of volatiles materials and hydrocarbons at the biomass of DRP it was at about $200^{\circ} \mathrm{C}$ as can see at Fig. 1 (step 1) (Ceylan and Kazan, 2015). This stage it was followed by thermal decomposition what means that the biomass has thermal stability (Turmanova et al., 2008), followed by a major loss of mass in the temperature range of 200 and $370{ }^{\circ} \mathrm{C}$ releasing the volatiles organics, characterizing the devolatilisation processes (step 2) (Damartzis et al., 2011).

The step 3 about $350^{\circ} \mathrm{C}$ shows thermal degradation of DRP of some carbohydrates such as cellulose and others and the step 4 its associated at thermal decomposition of cellulose and lignin at about $400{ }^{\circ} \mathrm{C}$ (Damartzis et al., 2011; Sasmal et al., 2013). The lignin decomposition begins at the below temperatures and up to $550{ }^{\circ} \mathrm{C}$. This high temperature is associated with the thermal stability and is responsible for the biomass degradation and residues during the decomposition process (Burhenne et al., 2013).

The presence of lowest cellulose content contributes to the less crystalline structure and recalcitrant characteristics of the material. The decomposition of biomass with high lignin content presents endothermic reaction, whereas decomposition of herbaceous biomass, with lower lignin content, involves an exothermic reaction (Yang et al., 2006).

The correlation between biomass and the cellulose, hemicellulose and lignin fractions was not very accurate (Couhert et al., 2009). Nevertheless, since the components differ significantly in their decomposition behavior, it is possible to determine clear trends in decomposition time, reaction enthalpy and composition of any biomass according to its composition of lignin, cellulose and hemicellulose (Ranzi et al., 2008). After step 4 occurs oxide formation.

In the temperature range of $200{ }^{\circ} \mathrm{C}$ and $500{ }^{\circ} \mathrm{C}$ it was a thermal decomposition of flavonoid and phenolic presents at capsaicinoids, as well fatty acids, (i.e. Linoleic, Oleic and Palmitic acids) and they become typical products of lignin decomposition.

\subsection{Kinetic studies}

The kinetic of thermal decomposition of biomass is an important component in the efficient design of thermochemical processes for the conversion of biomass (Turmanova et al., 2008). These processes have mechanisms very often unknown or too complex to be characterized by a simple kinetic model. They tend to occur in multiple steps that have different rates and to describe their kinetics, isoconversional methods are often used (Vyazovkin and Sbirrazzuoli, 2006).

The superposition of the decomposition of the single components it was used to predict thermal and kinetic behavior of biomass from its composition simply (Burhenne et al., 2013).

The Fig. 2 represents the curves of conversion degree $v s$. temperature at different heating rates, $5^{\circ} \mathrm{C} / \mathrm{min}(\mathrm{A}), 7.5^{\circ} \mathrm{C} / \mathrm{min}$ (B) and $10^{\circ} \mathrm{C} / \mathrm{min}(\mathrm{C})$ in air atmosphere and the prediction does exhibits a good agreement with experimental data. Thanks to these results, the conversion degree and mass loss values can be used in order to better understand the biomass behaviors.

Two different stages can be observed in the process and they characterize a heterogeneous process and the lower heating rate, lower is the temperature at which they occur (Salla et al., 2003). The first stage, at lower temperature, in the temperature range $450-575 \mathrm{~K}$ is associated with thermal degradation of the biopolymers (i.e. cellulose) and the second at temperature $575 \mathrm{~K}$, with degradation of the carbonaceous matter formed in the first stage (Leroy et al., 2010; Salla et al., 2003). 

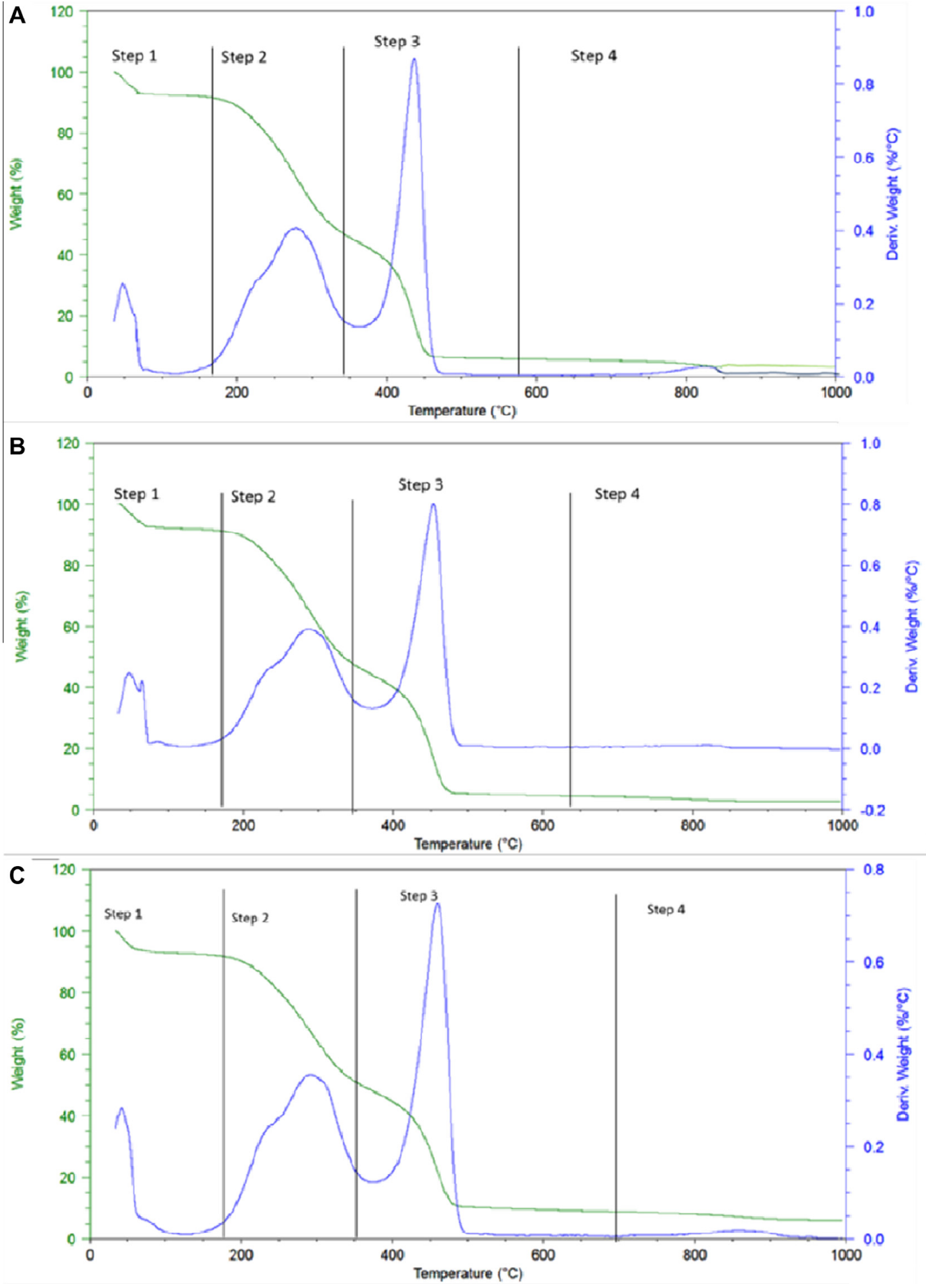

Fig. 1. Devolatilisation stages of RPW with heating rate of $5{ }^{\circ} \mathrm{C} / \mathrm{min}(\mathrm{A}), 7.5^{\circ} \mathrm{C} / \mathrm{min}(\mathrm{B})$ and $10^{\circ} \mathrm{C} / \mathrm{min}(\mathrm{C})$ in air atmosphere.

Data from TG and DTG curves in the decomposition range $0.1<\alpha<0.9$ were used to determine the kinetic parameters of the process in all used calculation procedures. The Fig. 3 represents $\ln \beta$ versus $\alpha(1 / T)$ using TG curves presents in Fig. 1. During the thermal degradation of this biomass the energy barrier has to be overcome and can be observed that at the initial process, before the thermal process, all of bonds are not modified.
The estimate of the activation energy released chemical reactions complicated by physical transformations of biomass, the chemical stability of a compound is directly proportional to the value of activation energy.

Therefore, to ensure the decomposition of the stable molecules presents in that biomass, it is necessary to supply more energy, because is already know that during the decomposition of these 


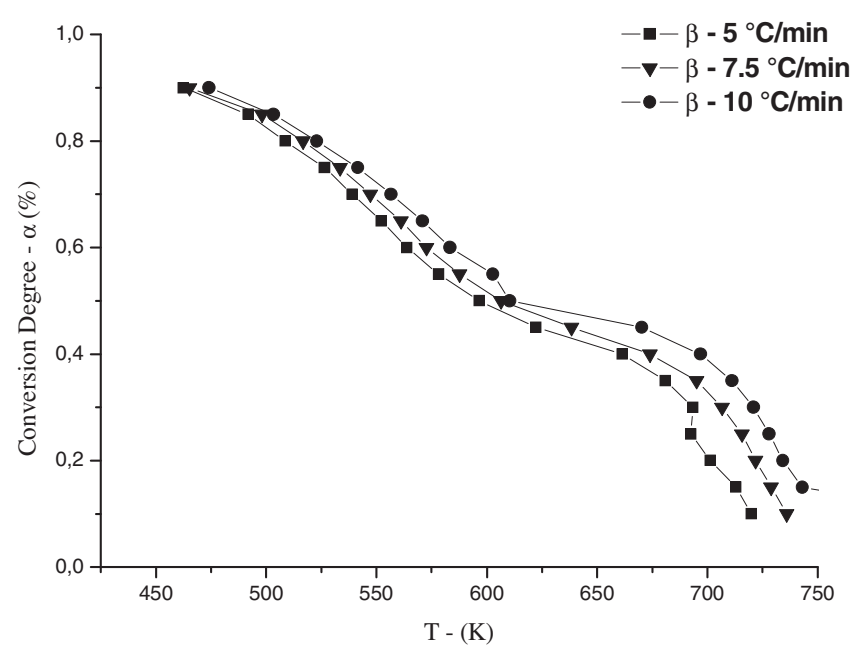

Fig. 2. Curves of conversion degree vs. temperature at different heating rates.

stable molecules at high temperature, less stable molecules which are easier to decompose are formed resulting in the lowering of heat supply.

It is already know that there are molecules easier to decompose and they are formed at higher temperature and the value of the activation energy decreases with the increase of conversion processes.

The apparent activation energy varied with increasing conversions and that shows volatiles degradation about $\alpha$ 50-85\% (Manikandan et al., 2012). Thus, the DRP biomass presents two small values of activation energy in the range $\alpha 10$ and $45 \%$ between $29.49 \mathrm{~kJ} / \mathrm{mol}$ and $47.83 \mathrm{~kJ} / \mathrm{mol}$. The variation of values of activation energies are not similar at different constant extents of conversion because most solid-state reactions are not simple one-step mechanism and follow a complex multi-step reaction (Heydari et al., 2015).

According (Markovska et al., 2010), values of the activating energy found on the range of $60-120 \mathrm{~kJ} / \mathrm{mol}$ are comparatively low. These values indicate that higher activation energy is only needed to decompose biomass with higher lignin content (Burhenne et al., 2013).

In lignocellulosic biomass the activation energy can vary from $80 \mathrm{~kJ} / \mathrm{mol}$ to $200 \mathrm{~kJ} / \mathrm{mol}$ to hemicellulose, $195-286 \mathrm{~kJ} / \mathrm{mol}$ to cellu-

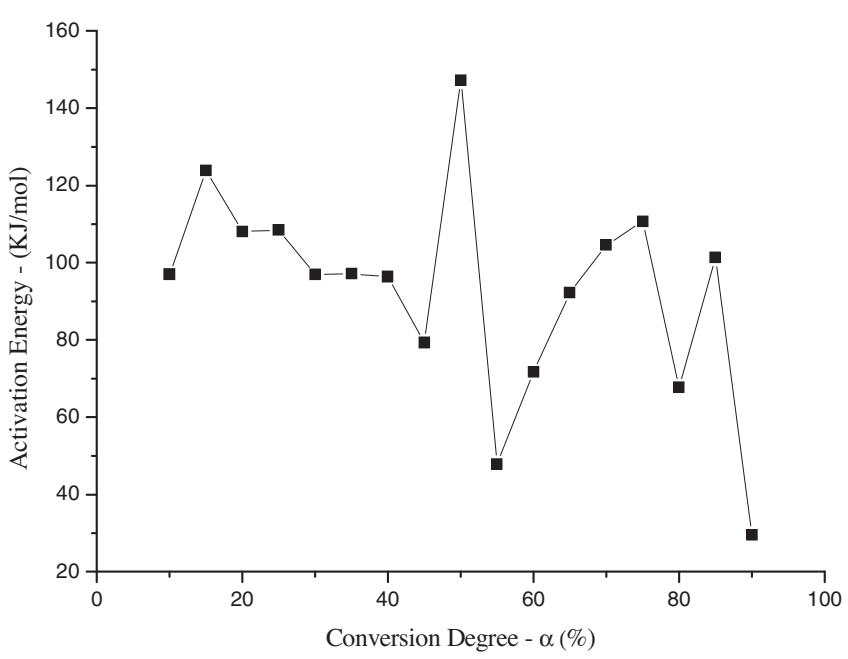

Fig. 4. Changes of Activation Energy during the biomass degradation process.

lose and $18-65 \mathrm{~kJ} / \mathrm{mol}$ to lignin. The apparent activation energies of RPW varied from $29.49 \mathrm{~kJ} / \mathrm{mol}$ to $147.25 \mathrm{~kJ} / \mathrm{mol}$. Olive residue and sugar cane bagasse have a value of $153-162 \mathrm{~kJ} / \mathrm{mol}$ and $168-$ $180 \mathrm{~kJ} / \mathrm{mol}$, respectively, due to the hemicellulose degradation, rice straw have a $166.98 \mathrm{~kJ} / \mathrm{mol}$ and rice bran $115.124 \mathrm{~kJ} / \mathrm{mol}$ (Xu and Chen, 2013).

The initial activation energy value was considered low due to cleavage of some weak bonds and elimination of volatile components from the biomass because at the beginning of the process all the strong bonds are not cleaved (Gašparoviè, 2012; Markovska et al., 2010).

It was also observed decreasing dependences when studying the thermal degradation of biomass and interpreted this fact as the transition of the process in air atmosphere (Leroy et al., 2010).

The Fig. 4 represents the values of $E_{\alpha}$ during the process. The changes of enthalpies revealed the energy difference between the reagent and the activated complex agreed with activation energies (Dweck, 2008). The variation of enthalpy as well as respective activation energy changes represents the residual carbonaceous material (Turmanova et al., 2008). The change of activation enthalpy also shows the energy differences between the activated complex and the reagents. If this difference is small, the formation of acti-

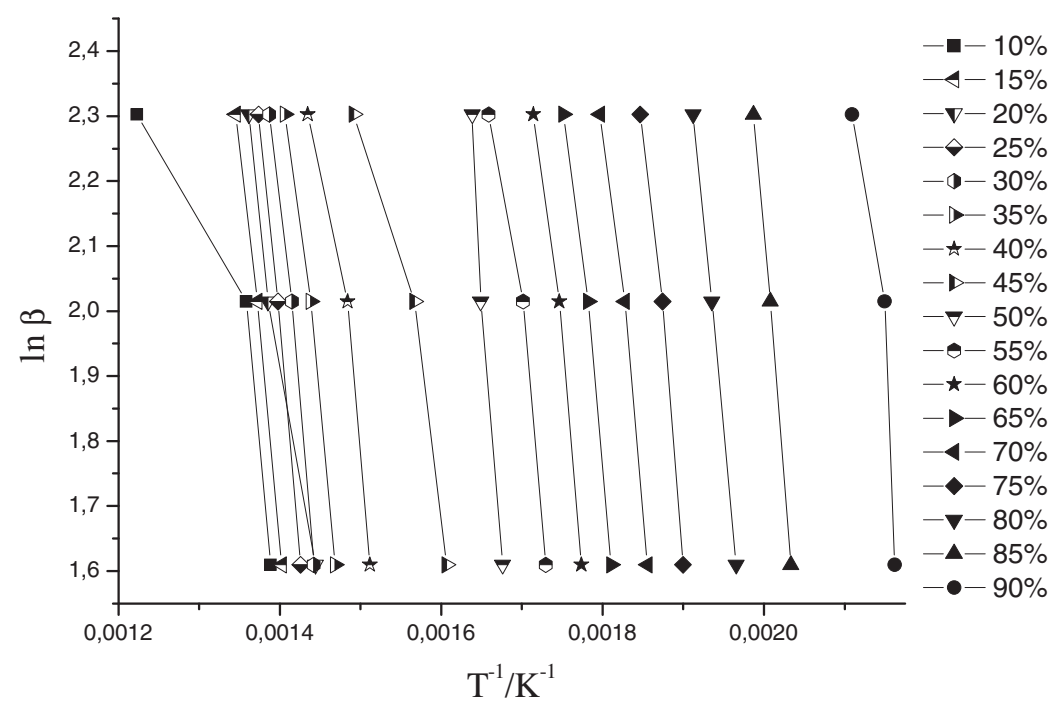

Fig. 3. Ozawa-Flynn-Wall isoconversion method applied to the thermal processing TG data of RPW in open pans within $10-90 \%$ of conversion. 
Table 1

Kinetic Parameters of RPW with heating rate of $5{ }^{\circ} \mathrm{C} / \mathrm{min}(\mathrm{A}), 7.5^{\circ} \mathrm{C} / \mathrm{min}(\mathrm{B})$ e $10^{\circ} \mathrm{C} / \mathrm{min}(\mathrm{C})$ in air atmosphere.

\begin{tabular}{|c|c|c|c|c|c|}
\hline Conversion degree $(\alpha)$ & $E_{\mathrm{a}}(\mathrm{kJ} / \mathrm{mol})$ & $A\left(\mathrm{~s}^{-1}\right)$ & $\Delta H(\mathrm{~kJ} / \mathrm{mol})$ & $\Delta G(\mathrm{~kJ} / \mathrm{mol})$ & $\Delta S(\mathrm{~J} / \mathrm{mol})$ \\
\hline $10 \%$ & 29.49 & $3.80 \mathrm{E}+00$ & 23.37 & 207.03 & -249.52 \\
\hline $15 \%$ & 101.33 & $1.98 \mathrm{E}+06$ & 95.27 & 198.08 & -141.03 \\
\hline $20 \%$ & 67.73 & $5.86 \mathrm{E}+03$ & 61.73 & 197.70 & -188.37 \\
\hline $25 \%$ & 110.67 & $1.47 \mathrm{E}+07$ & 104.73 & 192.92 & -123.24 \\
\hline $30 \%$ & 104.51 & $6.30 \mathrm{E}+06$ & 98.64 & 138.59 & -56.52 \\
\hline $35 \%$ & 92.17 & $9.10 \mathrm{E}+05$ & 86.39 & 112.16 & -37.06 \\
\hline $40 \%$ & 71.77 & $3.28 \mathrm{E}+04$ & 66.17 & 71.77 & -8.31 \\
\hline $45 \%$ & 47.83 & $5.44 \mathrm{E}+02$ & 42.53 & 104.89 & -97.69 \\
\hline $50 \%$ & 147.25 & $1.11 \mathrm{E}+12$ & 142.21 & 159.51 & -28.53 \\
\hline $55 \%$ & 79.31 & $1.46 \mathrm{E}+06$ & 74.42 & 157.38 & -141.14 \\
\hline $60 \%$ & 96.35 & $1.03 E+08$ & 91.60 & 151.85 & -105.23 \\
\hline $65 \%$ & 97.16 & $1.95 \mathrm{E}+08$ & 92.50 & 148.47 & -99.76 \\
\hline $70 \%$ & 96.93 & $3.30 \mathrm{E}+08$ & 92.38 & 144.46 & -95.17 \\
\hline $75 \%$ & 108.48 & $9.04 \mathrm{E}+09$ & 104.04 & 140.03 & -67.44 \\
\hline $80 \%$ & 107.99 & $1.90 \mathrm{E}+10$ & 103.69 & 136.24 & -62.98 \\
\hline $85 \%$ & 123.88 & $2.80 \mathrm{E}+12$ & 119.74 & 129.30 & -19.20 \\
\hline $90 \%$ & 97.04 & $2.01 \mathrm{E}+10$ & 93.17 & 105.49 & -26.49 \\
\hline
\end{tabular}

vated complex is favored, because the potential energy barrier is low (Vlaev et al., 2007).

The enthalpy variation of RPW was between $23.37 \mathrm{~kJ} / \mathrm{mol}$ and $142.21 \mathrm{~kJ} / \mathrm{mol}$ and it was already determined that rice bran have $111.03 \mathrm{~kJ} / \mathrm{mol}$ of $\Delta \mathrm{H}$, rice straw have $162.23 \mathrm{~kJ} / \mathrm{mol}$ and chicken manure presents $165.45 \mathrm{~kJ} / \mathrm{mol}$ (Xu and Chen, 2013).

\subsection{Thermodynamic parameters}

The Table 1 shows the kinetic parameters at the point of maximum conversion. The pre-exponential factor values for solid phase reactions are expected to be in range $10^{6}$ and $10^{7}$ and are directly related with material structure while the reactivity of samples is determined by the activation energy (Vlaev et al., 2007).

The value ranged from $10^{4}$ to $10^{18} \mathrm{~s}^{-1}$ showed empirical first order pre-exponential factors. The parameter showed variations to conversion rates. This may be described to the complex composition of the samples and the complex reactions that occur during decomposition (Turmanova et al., 2008).

The low pre-exponential factors $\left(<10^{9} \mathrm{~s}^{-1}\right)$ may indicate mainly a surface reaction, but if the reactions are not dependent on surface area, the low factor may indicate a closed complex. The high factors indicate a simple complex $\left(\geqslant 10^{9} \mathrm{~s}^{-1}\right)$ (Turmanova et al., 2008). The values of $A$ between $10^{10}$ and $10^{12} \mathrm{~s}^{-1}$ reveals the activated complex was probably restricted in rotation compared to the initial reagent (Xu and Chen, 2013).

The value of pre-exponential factor less than $10^{4}$ shows lower activation energy values, in this case $29.49 \mathrm{~kJ} / \mathrm{mol}$ and $67.73 \mathrm{~kJ} / \mathrm{mol}$ and represents the degradation of hemicellulose which occurs in steps 1 and 2 . These lower values in $A$ and $E_{\alpha}$ indicate a faster and easier degradation effect of this biomass for the respective degrees of conversion (Santos et al., 2015a).

The values showed in this study presents all range above, showing that the biomass studied is complex, as well all the phases of degradation can occur during the reaction. The range of preexponential factor for RPW was from $3.80 \mathrm{E}+00$ to $2.80 \mathrm{E}+12$. Rice straw presents values of pre-exponential factor between $1.70 \mathrm{E}$ +07 and $9.35 \mathrm{E}+12$, rice bran presents $1.00 \mathrm{E}+07$ and $1.58 \mathrm{E}+10$ and chicken manure presents values between $1.00 \mathrm{E}+07$ and $1.27 \mathrm{E}+13$ (Xu and Chen, 2013).

The lower value of the apparent activation energy and preexponential factors of thermal degradation of biomass was due to the significant amount of porous carbon. This porous carbon easily burns in oxidative atmosphere and facilitates the thermal degradation of the red pepper waste (Turmanova et al., 2008).
Changes of entropies showed in Table 1 had negative values, indicating that the degree of disorder of products formed through bond dissociations was lower than that of initial reactants. The $\Delta \mathrm{S}$ from RPW varied from $-8.31 \mathrm{~J} / \mathrm{mol}$ to $-249.52 \mathrm{~J} / \mathrm{mol}$ and showed higher values than rice straw and rice bran, $-4.13 \mathrm{~J} / \mathrm{mol}$ and $-62.14 \mathrm{~J} / \mathrm{mol}$, respectively.

Low activation entropy meant that the material has just passed through some kind of physical or chemical aging process, bringing it to a state near its own thermodynamic equilibrium. In this situation, the material shows little reactivity, increasing the time taken to form the activated complex. On the other hand, when high activation entropy values are observed, the material is far from its own thermodynamic equilibrium. In this case, the reactivity is high and the system can react faster to produce the activated complex, which resulted in the short reaction times observed (Turmanova et al., 2008).

The changes of the Gibbs free energy showed the total energy increase of the system at the approach of the reagents and the formation of the activated complex (Kim et al., 2010; Sheng et al., 2014; Turmanova et al., 2008). The Gibbs free energy varied from $71.77 \mathrm{~kJ} / \mathrm{mol}$ and $207.03 \mathrm{~kJ} / \mathrm{mol}$ from RPW. The same parameters showed to rice straw $164.59 \mathrm{~kJ} / \mathrm{mol}$, rice bran $167.17 \mathrm{~kJ} / \mathrm{mol}$ and chicken manure 175. $29 \mathrm{~kJ} / \mathrm{mol}$ (Xu and Chen, 2013).

The biomass calorific value estimated was $19.5 \mathrm{MJ} / \mathrm{kg}$ and this value is very similar with calorific values calculated for wood, $19.1 \mathrm{MJ} / \mathrm{kg}$, Lignite chars $20.8 \mathrm{MJ} / \mathrm{kg}$, coal $28.2 \mathrm{MJ} / \mathrm{kg}$, Palm olive kernel $20.4 \mathrm{MJ} / \mathrm{kg}$, Forest residue $21.7 \mathrm{MJ} / \mathrm{kg}$ and Cotton residue $18.3 \mathrm{MJ} / \mathrm{kg}$, according (Kastanaki and Vamvuka, 2006).

\section{Conclusions}

The potential use of red pepper waste as solid biofuel was appropriated and this product could be used in the industrial processes, favoring an agro-industry based competitive world economy. It was found that the presence of oxygen increased the value of the apparent $E_{\alpha}$ and decreased the peak temperature and the activation energies calculated from the TG had the highest values in the order of $147.25 \mathrm{~kJ} / \mathrm{mol}$. The variation of apparent $E_{\alpha}$ represent a multi-step kinetics on the degradation process The $A$ shows a first order reaction varying from $3.28 \mathrm{E}+04 \mathrm{~s}^{-1}$ to $2.80 \mathrm{E}$ $+12 \mathrm{~s}^{-1}$. The $\Delta S$ varied from $-8.31 \mathrm{~J} / \mathrm{mol}$ to $-249.52 \mathrm{~J} / \mathrm{mol}$ showed that the biomass has a high degree of arrangement and had physical and/or chemical process. The energy content of biomass was $19.5 \mathrm{MJ} / \mathrm{kg}$. The OFW model is in good accordance with the exper- 
imental data and satisfactorily described the complexity of degradation process.

\section{Acknowledgements}

The authors acknowledge the financial support provided by Brazilian Research Agencies: FAPESP, CNPq and CAPES.

\section{References}

Burhenne, L., Messmer, J., Aicher, T., Laborie, M., 2013. The effect of the biomass components lignin, cellulose and hemicellulose on TGA and fixed bed pyrolysis. J. Anal. Appl. Pyrol. 101, 177-184.

Ceylan, S., Kazan, D., 2015. Pyrolysis kinetics and thermal characteristics of microalgae Nannochloropsis oculata and Tetraselmis sp. Bioresource Technol. 187, $1-5$.

Ceylan, S., Topçu, Y., 2014. Pyrolysis kinetics of hazelnut husk using thermogravimetric analysis. Bioresource Technol. 156, 182-188.

Conesa, J.A., Urueña, A., Díez, D., 2014. Corn stover thermal decomposition in pyrolytic and oxidant atmosphere. J. Anal. Appl. Pyrol. 106, 132-137.

Couhert, C., Commandre, J., Salvador, S., 2009. Is it possible to predict gas yields of any biomass after rapid pyrolysis at high temperature from its composition in cellulose, hemicellulose and lignin ? Fuel 88, 408-417.

Damartzis, T., Vamvuka, D., Sfakiotakis, S., Zabaniotou, A., 2011. Thermal degradation studies and kinetic modeling of cardoon (Cynara cardunculus) pyrolysis using thermogravimetric analysis (TGA). Bioresource Technol. 102, 6230-6238.

di Blasi, C., 2009. Combustion and gasification rates of lignocellulosic chars. Prog. Energy Combust. Sci. 35, 121-140.

Dweck, J., 2008. Qualitative and quantitative characterization of Brazilian natural and organophilic clays by thermal analysis. J. Therm. Anal. Calorim. 92, 129135.

Font, R., Fullana, A., Conesa, J., 2005. Kinetic models for the pyrolysis and combustion of two types of sewage sludge. J. Anal. Appl. Pyrol. 74, 429-438.

Food and Agriculture Organization. Food wastage footprint: impacts on natural resources. Available in: <http://www.fao.org/docrep/018/i3347e/i3347e.pdf>. Accessed in October, 2015.

Freibauer, A., Mathijs, E., Brunori, G., Damianova, Z., Faroult, E., Gomis, J., Girona, O. L., Treyer, S., 2011. Sustainable food consumption and production in a resourceconstrained world. 3. ed. Belgium: [s.n.].

García, C.C., 2011. Fruit characteristics, seed production and pollen tube growth in the wild chilli pepper Capsicum flexuosum. Flora 206, 334-340.

Gašparoviè, L., 2012. Calculation of kinetic parameters of the therma decomposition of wood by distributed activation energy model (DAEM).). Chem. Biochem. Eng. Q. 26, 45-53.

Heydari, M., Rahman, M., Gupta, R., 2015. Kinetic study and thermal decomposition behavior of lignite coal. Int. J. Chem. Eng. 2015, 9.

Kastanaki, E., Vamvuka, D., 2006. A comparative reactivity and kinetic study on the combustion of coal - biomass char blends. Fuel 85, 1186-1193.

Kim, Y.S., Kim, Y.S., Kim, S.H., 2010. Investigation of thermodynamic parameters in the thermal decomposition of plastic waste-waste lube oil compounds. Environ. Sci. Technol. 44, 5313-5317.
Lee, H.V., Hamid, S.B.A., Zain, S.K., 2014. Conversion of lignocellulosic biomass to nanocellulose: structure and chemical process. Sci. World J. 2014, 20.

Leroy, V., Cancellieri, D., Leoni, E., Rossi, J.L., 2010. Kinetic study of forest fuels by TGA: model-free kinetic approach for the prediction of phenomena. Thermochim. Acta 497, 1-6.

Lian, F., Sun, B., Song, Z., Zhu, L., Qi, X., Xing, B., 2014. Physicochemical properties of herb-residue biochar and its sorption to ionizable antibiotic sulfamethoxazole. Chem. Eng. J. 248, 128-134.

Manikandan, G., Jayabharathi, J., Rajarajan, G., Thanikachalam, V., 2012. Kinetics and vaporization of anil in nitrogen atmosphere - non-isothermal condition. J. King Saud Univ. Sci. 24, 265-270.

Manyà, J.J., Arauzo, J., 2008. An alternative kinetic approach to describe the isothermal pyrolysis of micro-particles of sugar cane bagasse. Chem. Eng. J. 139, 549-561.

Markovska, I.G., Bogdanov, B., Nedelchev, N.M., Gurova, K.M., Zagorcheva, M.H., Lyubchev, L.A., 2010. Study on the thermochemical and kinetic characteristics of alkali treated rice husk. J. Chinese Chem. Soc. 57, 411-416.

Milagres, R.C.R.M., 2014. Effect of gamma radiation from 60 Co in the conservation and quality of pepper fresh and pulp. J. Chem. Inf. Model. 53, 121.

Ranzi, E., Cuoci, A., Faravelli, T., Frassoldati, A., Migliavacca, G., Pierucci, S., Sommariva, S., 2008. Chemical kinetics of biomass pyrolysis. Energy Fuel. 22, $4292-4300$

Salla, J.M., Morancho, J.M., Cadenato, A., Ramis, X., 2003. Non-isothermal degradation of a thermoset powder coating in inert and oxidant atmospheres. J. Therm. Anal. Calorim. 72, 719-728.

Santos, C.M., Dweck, J., Viotto, R.S., Rosa, A.H., Morais, L.C., 2015a. Application of orange peel waste in the production of solid biofuels and biosorbents. Bioresource Technol. 196, 469-479.

Santos, R.M., Santos, A.O., Sussuchi, E.M., Nascimento, J.S., Lima, A.S., Freitas, L.S. 2015b. Pyrolysis of mangaba seed: production and characterization of bio-oil. Bioresource Technol. 196, 43-48.

Sasmal, S., Goud, V.V., Mohanty, Y.K., 2013. Determination of salutary parameters to facilitate bio-energy production from three uncommon biomasses using thermogravimetric analysis. J. Therm. Anal. Calorim. 111, 1649-1655.

Sheng, J., Ji, D., Yu, F., Cui, L., Zeng, Q., Ai, N., Ji, J., 2014. Influence of chemical treatment on rice straw pyrolysis by TG-FTIR. IERI Procedia. 8, 30-34. Šimon, P., 2004. Isoconversional methods: fundamentals, meaning and application. J. Therm. Anal. Calorim. 76, 123-132.

Turmanova, S.C., Genieva, S.D., Dimitrova, A.S., Vlaev, L.T., 2008. Non-isothermal degradation kinetics of filled with rise husk ash polypropene composites. Express Polym. Lett. 2, 133-146.

Vlaev, L.T., Georgieva, V.G., Genieva, S.D., 2007. Products and kinetics of nonisothermal decomposition of vanadium(IV) oxide compounds. J. Therm. Anal. Calorim. 88, 805-812.

Vyazovkin, S., Sbirrazzuoli, N., 2006. Isoconversional kinetic analysis of thermally stimulated processes in polymers. Macromol. Rapid Commun. 27, 1515-1532.

Xu, Y., Chen, B., 2013. Investigation of thermodynamic parameters in the pyrolysis conversion of biomass and manure to biochars using thermogravimetric analysis. Bioresource Technol. 146, 485-493.

Yang, H., Yan, R., Chen, H., Zheng, C., Lee, D.H., Liang, D.T., 2006. In-depth investigation of biomass pyrolysis based on three major components: hemicellulose, cellulose and lignin. Energy Fuel. 20, 388-393. 